\title{
Soft monetary policy in a sustainable economy as a rigid game
}

\author{
Inna Čábelková ${ }^{1,2 *}$ \\ ${ }^{1}$ Department of Trade and Finance, Faculty of Economics and Management, Czech University of Life \\ Sciences Prague, Kamýcká 129, 16500 Prague, Czech Republic \\ ${ }^{2}$ Faculty of Humanities, Charles University in Prague. Pátkova 2137/5, 18200 Prague, Czech Republic
}

\begin{abstract}
Over the past decade, central banks in a majority of developed countries injected astonishing amounts of money into national and international economies in the hope of helping real sectors and with worries of high inflation. Neither of these came true. This paper describes the reasons for such unusual dynamics using a case of the sustainable economy. The three factors considered include the increased propensity to save, the decreased money multiplier, and substantial growth in the financial markets. The mathematical model studies the effect of the new money created on the real sector via the effect on real consumption depending on the share of the new money received by the less and more affluent part of the population. The results suggest, that the higher is the proportion of new money allocated to the poorer part of the society, the higher is the effect of overall money on the real sector if the propensity to consume in this part of the population is held constant.
\end{abstract}

\section{Introduction}

After the financial crisis in 2007-2009, central banks of almost all developed countries practiced the policy of monetary easing and injected astonishing amounts of money into the relevant economies. In the 2020 year alone, the central banks of developed economies "printed" an astonishing \$14 trillion on top of the trillions of dollars injected into the economies after, and in response to the crisis of 2007-2009 [1]. This enormous inflow of new money is traditionally associated with higher inflation [2, 3]. However, no significant inflation was observed. Moreover, most of the countries, the Czech Republic included, were balancing on the border of deflation [4]. Allen and Geels [5] in this respect explained the decoupling of monetary policy and inflation by an increased propensity to save and increased labor supply caused by globalization. Similar results were received by Van Doorslaer and Vermeiren [6].

This paper further analyses the association between inflation and money supply from the perspective of the effects of printing new money on the real sector consumption depending on the share of the new money given to less affluent parts of the population. Methodologically the paper relies on deductive argumentation and mathematical modeling.

\footnotetext{
* Corresponding author: cabelkova@pef.czu.cz
} 
The results suggest that new money may be viewed as "perpetuum mobile" which, after the initial emission, are created and destroyed on financial markets, making little harm to the real economy in a form of inflation, and little good in a form of increased consumption. This Perpetuum mobile is however temporary. If most of the new money is directed to more affluent parts of the population, they are more likely to increase inflation in the financial markets while the positive effect on the real economy can be minimal.

\section{Materials and methods}

This paper relies on mathematical modeling and deductive argumentation to analyze the effects of money creation real consumption depending on the initial distribution of this money to "rich" and "poor" groups of the population that are differentiated according to their propensity to save and consume.

\subsection{The inflationary effect of newly-emitted money: What has changed?}

There are major factors that differentiate the current situation in developed countries from the one 20 years ago. First, in times of recession, endangered by losing their jobs or facing lowering incomes consumers postpone major purchasing of durable goods and reduce the expenses on necessities. The lowering aggregate demand pushes the prices down and creates the tendency for deflation. There was no such pronounced tendency in the countries where the printing money led to inflation or hyperinflation.

Second, the economic crisis increased the propensity to save $[7,8]$ at the expense of propensity to consume, caused by the unpredictable future and lower expectation for future incomes. Simply speaking, people and firms tried to return the debts if possible, save more money, and not take that many loans. On the other hand, the banks, faced with a higher risk of default on credits, had to make their criteria on loans stricter and choose more specifically to whom they will give the loan. These tendencies of both of the sides - the banks on one side and the people and firms on the other - led to the credit crunch, which reduced the money multiplier and effectively reduced the total amount of money in circulation. This money needed to be substituted by the money created by the central banks. In the times and countries with no efficient fractional reserve banking with extended reliance on loans, no money can be destroyed by not taking loans or returning the old ones.

The third reason why unprecedented money injections by the central banks did not lead to significant inflation in the developed economies over the last decade was the quick development of financial markets $[9 ; 10]$. Boosted by technological innovations, namely the invention of computers, the development of financial markets was unprecedented over the last 30 years. Not mentioning other roles, like enabling corporations to gain access to large amounts of capital without the necessity to apply for a loan in a commercial bank, enabling people to multiply their savings via investments in the financial markets, providing the financial institutions with a new source of income, etc., the financial markets offered new types of assets, on which people and institutions could spend their money, thus diverting this money from the real sector of the economy.

The idea is both simple and ingenious. The extra liquidity created by the central (and commercial) banks instead of going to the markets of goods and services, thus increasing demand and creating pressures for high inflation there, were redirected to the financial markets, where, they create the price bubbles, but the real sector, which most of the people care for more, stays unaffected. Till the time the financial bubble bursts, as happened in 1930, 2007 and several times in between. Yet, before that happens, financial markets can absorb vast amounts of liquidity. 


\section{Empirical model}

As is stated above, this role of financial markets to absorb excessive liquidity might be viewed positively to avoid inflation in the real sector. However, it can be viewed negatively from the point of view of boosting demand, the lowering of which was caused by the inequality of distributions of incomes between imaginary employers and employees presented in a simple model above. From the point of view of insufficient real-sector demand, the tendency of newly printed money to escape to the financial markets significantly reduces the effectiveness of this monetary mechanism to regulate the real economy and exposes the world economy to the supposedly coming long-term recession from which there will be no cure. Similarly, the unavoidable burst of the bubbles on financial markets will eventually endanger the whole banking sector, which may have unpredictable negative effects on the real economy. The question arises on how to avoid these unfavorable outcomes. One, and maybe the only, way which was (again temporarily) effective in the past is again to bailout the problematic banks with the money of a) the government, thus creating even more debt of taxpayers and reducing their purchasing ability in the future even more or b) the central bank, thus fueling another portion of new money to the economy, which eventually will arrive at the financial markets and the whole process will repeat itself. The new Perpetuum mobile would be created following the stages presented in the following process (see diagram 1).

Given that the whole process implies both creation and destruction of the new money in financial markets and the process is likely to be repeated, the question arises whether after the ith iteration of the whole cycle the amount of money will increase, decrease or stay the same. If by this cycle the financial markets can destroy more money than they created, the whole system represents an unprecedented mechanism to effectively neutralize and eventually destroy the new inflationary money. This mechanism did not exist before financial markets were developed. If not, the whole system will operate with increasing amounts of money in each subsequent iteration. In any case, within the iteration, the mechanism presented in diagram one enables effectively divert inflationary money from the real economy.

An interesting view on the described cycle would be from the point of view of insider trading and overall strategies of operating and accumulation of capital on financial markets. Here, the big experienced players (or possibly the players with insider information) would have more probability to survive the burst of the financial bubbles either because of adequate investment strategies, because of more information, or because of the high probability to be bailed out by the government in the case of companies which are "too big to fail". On the other hand, small, inexperienced investors with limited or no bargaining power to be bailed out are likely to lose. Thus, from the point of view of the creation of inequality, the whole cycle is likely to prefer "rich" at the expense of "poor", thus perpetuating and reinforcing the inequality. The few exceptions would be the "poor" investors organized to the investment funds or pension funds, who are either experienced enough to foresee the burst of the bubble or big enough to reach for government support in the case of failure. The recent experience from the USA, however, makes the author be skeptical that the government will bail out the pension schemes at least in this country. The situation in Europe might be different. 
Stage 1. New money (M) is created by the central bank due to the lack of demand and slowdown in the real sector economy.

Stage 2. This money will partially go to financial markets $\left(\mathrm{M}_{\mathrm{f}}\right)$ with the proportion $\beta$, then:

$$
\begin{gathered}
M_{f}=\beta^{*} M \\
\beta \leq 1
\end{gathered}
$$

the rest will go to the real sector:

$$
M_{r}=(1-\beta) * M
$$

Stage 3. If the real economy does not correspond to the rise of the prices of assets on financial markets and does not provide sufficient footage for the growth of the asset prices the bubble on financial markets accumulates. The money created by the central bank that went to the financial markets is multiplied by the banking sector and via leverage trading. The resulting newly created amount of money that is operating on the financial markets equals to:

Where $m$ is the real money multiplier and

$$
M_{f}=m * \beta * M
$$

$$
1 \leq \mathrm{m} \leq 1 / \mathrm{RR}
$$

Where RR is the reserve ratio of commercial banks

Alternatively, if the currency drain ratio is taken into account

$1 \leq \mathrm{m} \leq(1+$ CurrencyDrainRatio $) /($ CurrencyDrainRation + DesiredReserveRatio)

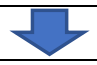

Stage 4. The bubble on financial markets bursts, significant wealth in the forms of assets is extinguished, but also a significant amount of money is deleted. To the knowledge of the author, there is no study quantifying whether the amount of money deleted was lower or greater than the initial amount of money created by the central bank and multiplied by the commercial financial institutions.

Stage 5. The central bank injects a new portion of the money into the economy to bail out the banks that were damaged on stage 4, and start the economy that is recovering from the last financial breakdown and the process starts anew.

Fig. 1. Money creation and destruction in the financial sector

Two things can be said about Figure 1: First of all, the author realizes, that the relationship of the outputs on the markets of goods and services and the prices of the assets on financial markets is not easy to describe and, in some time periods the financial markets seem to be completely detached from the markets of goods and services, which, according to the ideas of the author may correspond to the period of bubble creation, the author still has a hope to hypothesize, that if the real sector earning keep up with the earnings of the financial sector, the whole financial markets may be long term stable and not producing extended bubbles. This hypothesis, however is yet to be tested. Second, another assumption of this diagram is that the transfer of the liquidity from the market with real goods and services to the financial markets and back after the initial money injection of the central bank is zero. 
The unresolved question from the last exercise that remained to explain is what determines the parameter $\beta$, namely, which proportion of the newly created money will stay in the real economy and will be invested in the real sector production, and which proportion will be invested (most likely with appropriate leverage) on the financial markets.

Arguably the capital, if not regulated, goes to the sector with the highest possible returns. So, if in the real sector the distribution of income is highly unequal, the aggregate demand for real sector products and services falls (due to the negative relation of propensity to consume an income, as was explained above), which, if no significant technological innovation reducing costs happen, will lead to lowering returns to capital in the real economy. On the other hand, the returns to capital in financial markets are highly dependent on the flow of liquidity that is invested there according to the principle of a financial bubble. More money available lead to higher demand, which, if the supply of the financial instruments stays the same or does not grow that quickly, will drive the prices of financial instruments up and bring higher returns for the holders of the financial instruments if they sell them (the returns from dividends are not following this logic as they are more dependent on the real outcomes of the enterprises). The bigger is the return to financial capital the more new money is invested, which increases the demand for financial instruments even more and the whole process repeats itself. The side effect is also that the capitalizations of the enterprises increase, meaning they can take even more credits and invest them into the financial markets again, which creates another smaller upward-directed spiral. Obviously, there will come a point when no new money is available, or when, for some reason, investors lose their trust in financial instruments. In this case the bubble bursts.

To describe the processes above more formally, imagine the following model:

Let $\mathrm{M}$ be new money injected into the economy possibly because of a new financial stimulus of the central bank. This money by some economic mechanisms, which we will not describe here will eventually arrive to two groups of people. The first, for the sake of the model, will be called "poor" and will get $\alpha^{*} \mathrm{M}$ of new money. The second, denoted as "rich", will get $(1-\alpha)^{*}$ M. So, $\alpha$ is the proportion of the whole money that arrives to poorer parts of the population and can be partly regulated by the government in various types of government policies. For example, so-called "helicopter money" that is highly discussed nowadays will more likely be targeted to the "poor" parts of the society or evenly for everybody. Similarly, all the ideas related to unconditional income or increase are also likely mostly to rich the "poor". An increase in state-financed retirement benefits will supposedly rich the whole population, but more effect on increased consumption will have in the poorer parts. The other possibilities are to increase the transfers for families with small children or other socially relevant policies. On the other hand, bailing out problematic commercial banks and other globalized firms will more likely help the "rich". It is necessary to note, that both of the types of policies increase budget deficit which will have to be repaid in the future by either increasing taxes, inflating the currency, currency devaluation (if the debt is in local currency but bought by foreign companies), or will be erased by the default on government debt as happened in Russia at the end of 90th.

Both groups (rich and poor) have two options what to do with the money - they can either consume or save (and eventually invest). The propensity to consume of the poor group of people (let us denote it $\beta p$ ) is likely to be much higher than that of the rich group of people (denoted as $\beta \mathrm{r}$, for more discussion on income and propensity to consume see [11]).

To be even more precise, it is important to note that some people that we would put to the category of rich can spend all the fortunes they have and are left with significant debts. These stories are frequently discussed in the mass media where the main heroes are singers, prize or lottery winners, and other types of people that got their fortune quickly. However, arguably these people will not stay rich for long, and though their consumption may be enormous in individual merits, it may be viewed as minor in the merits of countries or nations. 
For others, the proportions of new money, savings, and consumptions are listed in the following table (see Table 1).

Table 1. New money, consumption, and savings of "poor" and "rich" parts of the population

\begin{tabular}{|l|l|l|}
\hline & \multicolumn{1}{|c|}{ "poor" } & \multicolumn{1}{c|}{ "rich" } \\
\hline New money & $\alpha^{*} M$ & $(1-\alpha) * M$ \\
& $(1)$ & $(4)$ \\
\hline Consumption & $C_{p}=\beta_{p}{ }^{*} \alpha M$ & $C_{r}=\beta_{r} *(1-\alpha) * M$ \\
& $(2)$ & $(5)$ \\
\hline Savings & $S_{p}=\left(1-\beta_{p}\right) * \alpha * M$ & $S_{r}=\left(1-\beta_{r}\right) *(1-\alpha) * M$ \\
& $(3)$ & $(6)$ \\
\hline
\end{tabular}

In this case:

$$
\text { Consumption total }=C_{p}+C_{r}=\beta_{p}{ }^{*} \alpha^{*} M+\beta_{r} *(1-\alpha) * M=M^{*}\left(\alpha^{*}\left(\beta_{p}-\beta_{r}\right)+\beta_{r}\right)
$$

And, as it was stated above:

$$
\beta_{\mathrm{p}} \geq \beta_{\mathrm{r}}
$$

From the formulas, 7 and 8 it follows that the new consumption generated by the new money is a positive (in our case linear) function of $\alpha$ (which is the share of new money that is received by the poor part of the population), in case if the propensity to consume of the poor group of people $\left(\beta_{\mathrm{p}}\right)$ greater than the propensity to consume if rich $\left(\beta_{\mathrm{r}}\right)$. This latter is the case (formula 8 ). Thus, the higher is the income inequality, represented by $\alpha$, the lower is total consumption. This holds even in the case new money is printed.

\section{Discussion}

Let us be reminded, that lower consumption implies lower income of real sector firms, which, if not offset by the new technology that reduces costs of production, leads to lower returns to capital in the real sector and greater motivation to speculate on financial markets. Here it is also important to clarify one simplification that was made in the model and argumentation above. We did implicitly assume that most, or all the speculations on the financial markets do not affect the real economy, which is not always the case. One could imagine a situation when through financial markets a new high technology firm will get the funds for further development, which leads to more productive technology in the real world, which reduces the costs of production and increase returns to capital in the real economy. This was the former real meaning of financial markets - to design a mechanism to raise capital for the large projects in the real economy [12]. However, the development of the last 20 years and financial crises before (the famous crisis of the thirties of the last century and the smaller crises in between then and now) prove that financial markets are subject to the creation of significant bubbles, which divert astonishing amounts of liquidity from the real sector.

The other limitation of the argumentation above is that we do not consider the multiplication effects of the commercial banks which can multiply the money initially injected by the Central bank differently in case of consumption and investment. In fact, if the additional money is used for direct consumption, the immediate multiplication effect of the commercial banks caused by the fractional reserve system may be zero. The secondary multiplication effect may have its rationale in the idea, that the money, obtained by the seller of the good bought for the new money if stored in a bank, will increase its liquidity and 
possibility to issue more loans. The latter is the essence of a money multiplier. In the case of saving and investment, the money multiplication is more direct and obvious. New money may be included in the reserves which again will allow the banks to lend more.

The last limitation of the model and argumentation above is that we do not take into account the multiplication of the consumption after the first good bought for a newly created money is bought (and consumed). The seller of this goodwill gets the extra money which may increase his consumption as well, and so on. However, all the multiplication effects do not go against the main argumentation and just magnify the effects described above.

\section{Conclusions}

The emission of new money, or the strategies of central banks of quantitative easing bear hope of more economic growth, which, however, is often accompanied by higher inflation. The unprecedented quantitative easing and "printing" new money in most of the developed economies over the last 10 years did not bring either. This paper discussed the reasons why the economic dynamics in response to soft monetary policy over the last 10 years were so different from the one before. We suggested, that firstly, frightened by the last financial crisis, consumers postponed their purchases of goods, that were not considered necessary, thus diminishing the upward pressure on prices. Secondly, the increased propensity to save and return the loans taken before decreased the money multiplier which partly compensated the increase in the money base. Thirdly, the extensively growing financial markets absorbed excessive liquidity, again, diminishing the inflationary pressured on the market of real goods and services. The adverse side of this process is the limited effect of the new money on the real sector of the economy (as opposed to the financial one).

This paper developed a model, that shows, that the distribution of the effects of new money on the financial and real sectors depend on the share of this money received by more and less affluent parts of the public. The results suggest, that the effect of "printing" new money on the sustainable economy is highly contingent upon the share of the new money that reaches more and less affluent parts of the population. This paper may be interesting for both researchers and policymakers as well as sustainable economy specialsts.

\section{References}

1. A. Murphy, Economics-2020: What Happens When Everything Shuts Down Except the 'Money Printing Presses' (2020).

2. E. Dean, J. Elardo, M. Green, B. Wilson, S. Berger, Monetary Policy and Economic Outcomes. Principles of Economics: Scarcity and Social Provisioning (2020).

3. F. Collard, H. Dellas, Journal of Money, Credit and Banking, 39(2-3), 713-731 (2007).

4. J. H. Christensen, J. M. Gamble, J, S. Zhu, FRBSF Economic Letter, 11, 1-5. (2020).

5. E. M. Allen, H. J. Geels, https://papers.ssrn.com/sol3/papers.cfm?abstract_id=3763499 (2021)

6. H. Van Doorslaer, M. Vermeiren, New Political Economy, 1-20 (2020)

7. I. J. Dos Santos Felipe, Individual Behaviors and Technologies for Financial Innovations (2019)

8. O. Primierova, I. Abakumova. Naukovi zapiski NaUKMA: Econimichni Nauki, 159, $72-$ 78 (2014)

9. Y. Li, S. Wang, Q. Zhao, Finance Research Letters, 101642 (2020)

10. D. Schell, M. Wang, T. L. D. Huynh, Journal of Behavioral and Experimental Finance, 27, 100349 (2020) 
11. R. E. Hall, J. B. Taylor, Consumption and Income. Macroeconomics: Theory, Performance, and Policy (1986)

12. K. Pilbeam, Finance and Financial Markets (2010) 